\title{
Pyrolysis and catalytic steam gasification of olive oil waste in two stages
}

\author{
J. M. Encinar ${ }^{1}$, J.F. González ${ }^{2}$, G. Martínez ${ }^{1}$, M.J. Martín ${ }^{1}$ \\ ${ }^{1}$ Dpto. Ingeniería Química y Química Física. UEX. Avda. Elvas s/n. 06071-Badajoz. Spain \\ ${ }^{2}$ Dpto. Física Aplicada. UEX. Avda Elvas s/n. 06071-Badajoz. Spain \\ ${ }^{1}$ Tf.34-924-289672; fax 34-924-289385. E-mail address: jencinar@unex.es
}

\begin{abstract}
A study of the pyrolysis and catalytic gasification of a waste from the extraction of olive oil has been carried out. The work objective was to characterize the solid and gaseous phases generated in the process for their possible utilization in energy generation. The experimental system consists of two cylindrical stainless steel reactors connected in series. A conventional pyrolysis is produced in the first reactor. In the second reactor, the gases and liquids generated in the first one pass through a dolomite catalytic bed where the cracking of the heavier components is produced. Also, in this second reactor, a steam stream is continuously introduced. The influence of temperature $\left(500-700{ }^{\circ} \mathrm{C}\right)$, quantity of catalyst $(25-100 \mathrm{~g})$ and steam flow rate $(0-1.40 \mathrm{~mL} / \mathrm{min})$ has been determined. Also, the dolomite effectiveness as catalyst was evaluated For this motive, experiments, without reactivating dolomite, were carried out (0-6 runs), and the yields of solids, liquids and gases were determined. An increase in reaction temperature leads to a decrease in solid and liquid yield and to an increase in the gas phase yield. The presence of catalyst and the quantity of the same, originate an important decrease in the liquid phase yield and a high increase in the gas phase yield, especially important in the case of hydrogen. On the other hand, the catalyst is very stable and does not lose activity during at least six cycles of reaction. The presence of steam, increase the yield of hydrogen, but the increase of the steam flow rate, do not generate significant changes in the products distribution.
\end{abstract}

\section{Key words}

Pyrolysis, gasification, olive oil waste, dolomite

\section{Introduction}

Since environmental pollution is becoming an ever more serious problems associated with the great $\mathrm{CO}_{2}, \mathrm{NO}_{\mathrm{x}}$ and $\mathrm{SO}_{\mathrm{x}}$ emissions resulting from the rising use of fossil fuels. For this reason, it is important to consider making use of biomass as a clan and renewable substitute for fossil energy. Thus, residues, including those originating from the wood industry, forest and agricultural workings, paper manufacturing and, more recently, specifically different vegetal species which can generate energy, are renewable sources and an alternative to fossil combustibles [1].

Agricultural and forestry wastes and, in general, all biomass residues, can be used as raw materials for the generation of energy, chemicals and active carbon [2, 3]. Italy, Spain, Greece and Portugal stand for $75 \%$ of the world production of olive oil. The residues generated by the EU olive oil milling industry have been estimated to be 6.8 million tonnes/year [4]. The extraction process of olive oil produces a solid residue, after drying, with the solvent hexane. The residual oil, which is extracted, is called olive husk oil and the solid waste of this extraction is the exhausted olive oil husk (kernel). In Spain, the production of this residue, known as "alperujo", belongs to 3.5-4 million tonnes/year. Pyrolysis and gasification as thermochemical conversion technologies can be used to recover energy utilizing exhausted olive oil husks [4-6]. In the pyrolysis of agricultural residues (in general in the pyrolysis of biomass) three products are generated: tar, char and permanent gas. Among these products, tars are undesired products that can cause problems such as plugging, sooting and deposit formation. However, many studies on formation and catalytic cracking of the tars have been limited to study single species or the entire tar as a single lump. Recently, more advanced approaches have been developed for the catalytic tar elimination [4]. In general, the pyrolysis catalyzed processes give rise to an elevated hydrogen production. The catalyst, to high temperatures, exerts an effect of cracking and causes a larger generation of light gases. On the other hand, when temperatures are low, the unstable hydrocarbons react and liquid products are generated. Hence, using catalysts to elevated temperatures causes an elevated conversion of liquid compounds to gaseous compounds [7].

Dolomite is a catalyst of the named nonmetallic oxides. This catalyst has been investigated extensively as biomass gasification catalysts. Dolomite is a magnesium ore with the general formula $\mathrm{MgCO}_{3} \cdot \mathrm{CaCO}_{3}$ that contains about 30 wt. \% CaO, 20 wt. \% $\mathrm{MgO}$ and 45 wt. \% CO2 with other minor mineral impurities such as the trace minerals $\mathrm{SiO}_{2}, \mathrm{Fe}_{2} \mathrm{O}_{3}$ and $\mathrm{Al}_{2} \mathrm{O}_{3}$. Your use is very important since it is an inexpensive and abundant product. For this motive, several research groups have conducted extensive investigations on dolomites because of its good tar conversion effectiveness [8]. The catalytic activity of the dolomite calcined is more elevated than the activity of the natural dolomite. In order to accomplish the aforementioned calcination, the natural dolomite is submitted to $900{ }^{\circ} \mathrm{C}$ in inert atmosphere $\left(\mathrm{N}_{2}\right)$ during at least 8 hours [8].

With this background in view, and as the continuation to previous works where the pyrolysis of several 
agricultural and forestal residues was studied [9-11], we carried out a study of the pyrolysis and gasification of olive oil waste catalyzed by dolomite. Our aim was to characterise the solid, liquid and gaseous phase obtained in the pyrolysis process with a view to its energy use.

\section{Experimental methods and materials}

The experimental system consists of two cylindrical stainless steel reactors connected in series. A conventional pyrolysis takes place in the first reactor. In the second reactor a steam stream is continuously introduced. The gases and liquids generated in the first one pass through a dolomite catalytic bed where the cracking of the heavier components is produced. In addition, in the second reactor, the reaction with the water steam takes place The reactors are provided with heating system, inlet for feeding the gas and steam stream, and accessories to collect the liquid and gas phases. The heating system consisted of a ceramic furnace and power source. The temperature was controlled to within $\pm 2{ }^{\circ} \mathrm{C}$ automatically. All experiments were carried out isothermally. A suspension system of the basket that contains the samples of residue is set in the top of the first reactor. That way, the samples remain to ambient temperature before the start of the run. The basket was loaded with approximately $10 \mathrm{~g}$ of residue while positioned in the top of the first reactor. Then a gas flow of nitrogen was established at $150 \mathrm{mLmin}^{-1}$. This flow was maintained for a least $1 \mathrm{~h}$ to remove air from any part of the installation. After this period, the heating system was connected to reach the predesignated setpoint temperature. When the set-point temperature is achieved, the steam stream is introduced in the reactor Heating of samples can be considered instantaneous, since the basket was introduced into the heating zone of the reactor once the set-point temperature had been reached. The duration of the run, depending of the reaction conditions, was comprised between 30 and 150 minutes. During this time, samples of gases were withdrawn at regular intervals. When the run is finalized, the heating was switched off and the basket moved back to the top of the reactor. Once ambient temperature was reached, the weight of carbonaceous residue remaining in the basket and the amount of liquids obtained were measured. The solid and gas fractions were analysed later.

The gas fraction, mainly composed of $\mathrm{H}_{2}, \mathrm{CO}, \mathrm{CO}_{2}$ and $\mathrm{CH}_{4}$, and some low molecular weight hydrocarbons such as ethane and ethene, was analysed chromatographically with a 4000 HRGC Konik gas chromatograph provided with a thermal conductivity detector and a double injector connected to two columns: a $4.5 \mathrm{~m}$ stainless steel column (2.1 mm ID) packed with Carboxen 1000 of 60/80 mesh, and a $3 \mathrm{~m}$ stainless steel column (2.1 mm ID) packed with Porapak Q of 100/120 mesh. Helium and nitrogen were used as carrier gases respectively. The solid phase was characterized by proximate analysis, using an ASTM standards TGA method. A Parr 1351 bomb calorimeter was used to determine the high heating value (HHV) of the solid fraction.
The activation of dolomite is carried out by means of calcination at $900{ }^{\circ} \mathrm{C}$ in nitrogenous atmosphere. The process finish when the concentration of $\mathrm{CO}_{2}$ in the effluent gases be void. In this calcination, the original carbonates are transformed in calcium and magnesium oxides, that is, in the catalysts of the process

\section{Results and discussion}

The studied variables have been temperature (500-700 ${ }^{\circ} \mathrm{C}$ ), quantity of catalyst (25-100 g) and steam flow rate $\left(0-1.40 \mathrm{mLmin}^{-1}\right)$

Also, the dolomite effectiveness as catalyst was evaluated carrying out six consecutive experiments without reactivation of the catalyst. The proximate analysis, oven dry basis, of olive oil waste used as raw material give the following values: fixed carbon $21.1 \mathrm{wt} \%$, volatile matter $76.3 \mathrm{wt} \%$, and ash $2.6 \mathrm{wt} \%$. On the other hand, the higher heating values, also oven dry basis, was $18.2 \mathrm{MJ}$ $\mathrm{kg}^{-1}$.

In previous experiments, particle size was varied from 1.00 to $2.50 \mathrm{~mm}$ diameter and $\mathrm{N}_{2}$ flow rate between 100 and $300 \mathrm{~mL} \mathrm{~min}^{-1}$. The obtained results show that theses variables did not have any effect on the process rate. Hence, all experiments were carried out with a particle size of 2.00-2.50 mm diameter and a $\mathrm{N}_{2}$ flow rate of 150 $\mathrm{mL} \min ^{-1}$.

\section{A. Dolomite stability and activity}

A first aspect to consider in the experiments was the loss of activity of the dolomite as catalyst. For this motive, experiments, without reactivating dolomite, were carried out, and the yields of solids, liquids and gases were determined. In this set of experiments, the initial mass of residue was $10 \mathrm{~g}$, temperature $700^{\circ} \mathrm{C}$, the steam flow rate $1.40 \mathrm{mLmin}^{-1}$, and the mass of dolomite in the second reactor $100 \mathrm{~g}$. Table 1 list the fraction yields, the proximate analysis, and HHV of the chars for this sets of experiments. In obtaining the fraction yields by means of a mass balance, quantifying the liquid and the solid fractions by weight and the gas fraction from the detected gases, we achieved experimental errors not greater than $5 \%$ with respect to the initial mass. As can be observed, the yield of solids remains constant. This result is logical, since solids are not affected for the presence of dolomite. On the other hand, a little increase in the yield of liquids takes place (35.5 to $37.5 \mathrm{wt} \%$ ) and, logically, a decrease in the yield of gases (41.6 to $39.3 \%$ ). In any case these differences are not significatives. Obviously, the correspondent values to the proximate analysis (oven dry basis) and HHV remain invariable. So then, dolomite is quite stable and your activity remains basically constant.

The moles generated of every one of the gases, on the basis of one $\mathrm{kg}$ of olive waste (OW), are shown in table 2. Also the HHV of the gases on the same base of calculation is listed. Although the differences are not important, a decrease in the generation of hydrogen and an increase in the generation of the other gases are observed. The HHV remains unchanging, because the loss of $\mathrm{HHV}$, as a consequence of the decrease of 
hydrogen, is compensated by the increase in the generation of monoxide and methane. Hence, although the catalyst remains stable and active, a loss of selectivity toward the formation of hydrogen is observed.

Table 1. Checking the dolomite stability and activity. Fractions yields, proximate analysis and HHV of chars.

\begin{tabular}{|l|c|c|c|c|c|c|}
\hline $\begin{array}{l}\mathrm{N}^{\circ} \text { of experiments } \\
\text { with the same } \\
\text { dolomite }\end{array}$ & 1 & 2 & 3 & 4 & 5 & 6 \\
\hline Char, wt\% & 22.9 & 22.5 & 23.6 & 23.6 & 23.1 & 23.2 \\
\hline Liquid, wt\% & 35.5 & 36.3 & 36.1 & 35.8 & 36.7 & 37.5 \\
\hline Gas, wt\% & 41.6 & 41.2 & 40.3 & 40.6 & 40.2 & 39.3 \\
\hline Fixed Carb., wt\% & 86.4 & 86.9 & 86.4 & 86.1 & 85.8 & 85.9 \\
\hline Volatiles, wt\% & 7.2 & 6.6 & 6.9 & 7.2 & 7.2 & 7.1 \\
\hline Ash, wt\% & 6.4 & 6.5 & 6.7 & 6.7 & 7.0 & 7.0 \\
\hline HHVChar, MJkg $^{-1}$ & 30.7 & 29.7 & 30.5 & 30.4 & 30.1 & 30.3 \\
\hline
\end{tabular}

Table2. Checking the dolomite stability and activity. Gases production and $\mathrm{HHV}$ of gases.

\begin{tabular}{|l|c|c|c|c|c|c|}
\hline $\begin{array}{l}\mathrm{N}^{0} \text { of experiments } \\
\text { with the same } \\
\text { dolomite }\end{array}$ & 1 & 2 & 3 & 4 & 5 & 6 \\
\hline $\mathrm{H}_{2}$, moleskgOW $^{-1}$ & 20.5 & 19.7 & 18.7 & 17.7 & 16.8 & 16.5 \\
\hline $\mathrm{CO}_{\text {moleskgOW }}$ mol $^{-1}$ & 3.93 & 3.56 & 4.18 & 4.75 & 5.26 & 5.34 \\
\hline $\mathrm{CO}_{2}$, moleskgOW $^{-1}$ & 4.85 & 4.40 & 7.10 & 6.60 & 6.23 & 6.18 \\
\hline $\mathrm{CH}_{4}$, moleskgOW $^{-1}$ & 2.53 & 2.60 & 2.99 & 3.03 & 3.08 & 3.10 \\
\hline $\mathrm{HHV}_{\mathrm{MJkgOW}}^{-1}$ & 9.21 & 8.95 & 9.17 & 9.10 & 9.03 & 9.01 \\
\hline
\end{tabular}

\section{B. Quantity of catalyst influence}

For to study the influence of the catalyst mass, experiments with $0,25.13,50.04$ and $99.89 \mathrm{~g}$ of dolomite were accomplished. In this set of experiments, the initial mass of residue was $10 \mathrm{~g}$, temperature $700{ }^{\circ} \mathrm{C}$ and the steam flow rate $1.40 \mathrm{mLmin}^{-1}$. Table 3 lists the fraction yields, the proximate analysis and HHV of the chars. As can be observe, when the quantity of dolomite increases, a decrease in the yield of the liquid phase is produced, and logically, an increment in the yield of the phase gas has place. On the other hand, the presence of dolomite does not affect the proximate analysis, for that the contents in fixed carbon, volatile and ash is practically the same in all the experiments.

Table 3. Quantity of catalyst influence. Fractions yields, proximate analysis and HHV of chars.

\begin{tabular}{|l|c|c|c|c|}
\hline Dolomite mass, g & 0 & 25.13 & 50.04 & 99.89 \\
\hline Char, wt\% & 22.2 & 21.2 & 23.6 & 22.9 \\
\hline Liquid, wt\% & 47.7 & 44.8 & 40.7 & 35.5 \\
\hline Gas, wt\% & 30.1 & 34.8 & 35.7 & 41.6 \\
\hline Fixed Carb., wt\% & 86.5 & 85.4 & 86.8 & 86.4 \\
\hline Volatiles, wt\% & 7.4 & 8.3 & 7.2 & 7.2 \\
\hline Ash, wt\% & 6.1 & 6.3 & 6.0 & 6.4 \\
\hline${\text { HHVChar, } \text { MJkg }^{-1}}^{-1}$ & 28.8 & 28.6 & 28.9 & 30.7 \\
\hline
\end{tabular}

In relation with the production of gases, the Fig. 1 shows a representation of accumulated moles of hydrogen vs. time of reaction for each experiment of this series. As can be observed, as the quantity of dolomite is incremented, also the quantity of generated hydrogen increases. This is due to that progressively there is more quantity of active centers, which produce a larger effect of cracking on the condensable gases. Evolution in the course of time for the other gases follows similar tendencies to the shown in the Fig. 1, but the quantities generated of these gases are not affected for the presence of the catalyst. Table 4 lists the gas production. It is verified that an increase in the quantity of dolomite causes an increase to the generation of hydrogen and a little decrease in the generation of the rest of gases. As a consequence of this, a progressive increase of $\mathrm{HHV}$ takes place. Hence, the dolomite presence only affects the production of hydrogen, exerting a positive effect on the selectivity of formation of this gas.

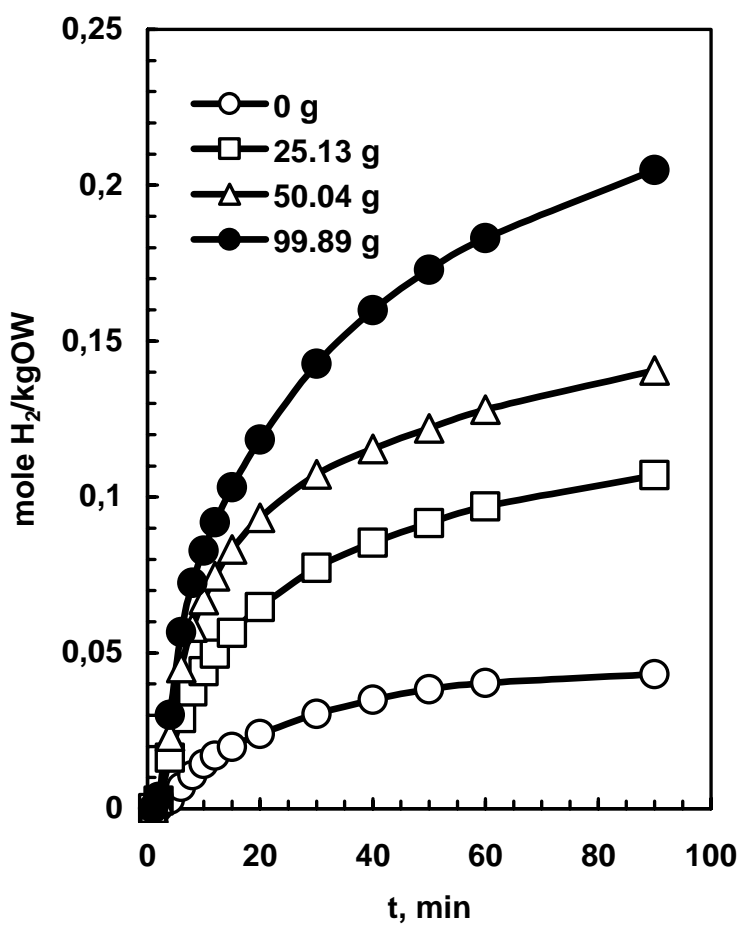

Figure 1. Production of hydrogen. Influence of catalyst mass.

Table4. Quantity of catalyst influence. Gases production and HHV of gases.

\begin{tabular}{|l|c|c|c|c|}
\hline Dolomite mass, g & 0 & 25.13 & 50.04 & 99.89 \\
\hline $\mathrm{H}_{2}$, moleskgOW $^{-1}$ & 4.31 & 10.70 & 14.06 & 20.5 \\
\hline $\mathrm{CO}$, moleskgOW $^{-1}$ & 5.83 & 3.53 & 3.83 & 3.93 \\
\hline $\mathrm{CO}_{2}$, moleskgOW $^{-1}$ & 4.48 & 4.29 & 4.06 & 4.85 \\
\hline $\mathrm{CH}_{4}$, moleskgOW $^{-1}$ & 3.21 & 2.48 & 2.71 & 2.53 \\
\hline $\mathrm{HHV}_{\mathrm{MJkgOW}}$ & 5.73 & 6.26 & 7.51 & 9.21 \\
\hline
\end{tabular}

\section{Temperature influence}

Three experiments (500, 700 and $800{ }^{\circ} \mathrm{C}$ ) were carried out to study the influence of the temperature. In this set of experiments, the initial mass of residue was $10 \mathrm{~g}$, the mass of dolomite in the second reactor $100 \mathrm{~g}$. and the steam flow rate $1.40 \mathrm{mLmin}^{-1}$ Table 5 list the fraction yields, the proximate analysis and HHV of the chars. 
As can be observed, the increase of temperature leads to a decrease in the yield of solids and liquids, and an increase in the yield of the gases fraction. As the temperature is raised, there is an increase in ash and fixed carbon percentages. Consequently, there is a decrease in volatile matter. Therefore, higher temperatures yield charcoals of greater quality, although the process yield diminishes. This effect was observed in our previous work on the pyrolysis of other lignocellulosic residues $[12,13]$, and also by other workers [14].

The char, with a mean HHV of $30.3 \mathrm{MJ} \mathrm{kg}^{-1}$, can be used as a solid fuel, as a precursor for activated carbon manufacture, and given that we determined the fixed carbon content to be $>80 \mathrm{wt} \%$, as the raw material to make category-A briquettes for domestic use according to French and Belgian standards $[15,16]$. The yield of the liquid phase is high; hence this fraction can be used as liquid fuel or like liquid- hydrocarbons source.

Table 5. Temperature influence. Fractions yields, proximate analysis and HHV of chars.

\begin{tabular}{|l|c|c|c|}
\hline Temperature, ${ }^{\circ} \mathrm{C}$ & 500 & 600 & 700 \\
\hline Char, wt\% & 29.3 & 25.6 & 22.9 \\
\hline Liquid, wt\% & 59.1 & 57.5 & 35.5 \\
\hline Gas, wt\% & 11.6 & 16.9 & 41.6 \\
\hline Fixed Carb., wt\% & 75.8 & 82.3 & 86.4 \\
\hline Volatiles, wt\% & 18.5 & 11.8 & 7.2 \\
\hline Ash, wt\% & 5.7 & 5.9 & 6.4 \\
\hline HHVChar, MJkg $^{-1}$ & 29.7 & 30.4 & 30.7 \\
\hline
\end{tabular}

As an example, Fig 2 shows the evolution of hydrogen concentration with reaction time at different temperatures. As can be seen, an increase of temperature results in increasing values of the maximum hydrogen concentration. It can also be deduced that the total moles of hydrogen generated during the process (proportional to the area under the curve) increase with increasing temperature. Release of hydrogen mainly occurs during the first 40-45 min of reaction so that for time longer than $45 \mathrm{~min}$, production of this gas is very small. The evolution of the other gases was similar.

Table 6 lists the influence of temperature on the gas production and the $\mathrm{HHV}$ of the gas fraction. As it is indicated, the gases were mostly hydrogen, carbon monoxide, methane and carbon dioxide. An increase of temperature led to increases in practically all gases, with a concomitant increase in the HHV of the total effluent gas. This gas of low/medium heating value can be used to heat the pyrolysis reactor or to generate heat and electricity in a gas-turbine/vapour-turbine combined cycle.

Between the studied parameters, probably temperature is the most determining. Effectively, it can be verified that the increments in temperature originate large variations in the production of all the gases. This circumstance is especially important in the case of hydrogen, whose

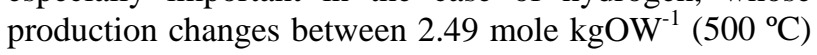

to 20.5 mole $\mathrm{kgOW}^{-1}\left(700{ }^{\circ} \mathrm{C}\right)$. As a consequence of the above, drastic changes are produced in the HHV.

Table6. Temperature influence. Gases production and HHV of gases.

\begin{tabular}{|l|c|c|c|}
\hline Temperature, ${ }^{\circ} \mathrm{C}$ & 500 & 600 & 700 \\
\hline $\mathrm{H}_{2}$, moleskgOW $^{-1}$ & 2.49 & 7.26 & 20.5 \\
\hline $\mathrm{CO}$, moleskgOW $^{-1}$ & 2.94 & 3.26 & 3.93 \\
\hline $\mathrm{CO}_{2}$, moleskgOW $^{-1}$ & 0.32 & 0.82 & 4.85 \\
\hline $\mathrm{CH}_{4}$, moleskgOW $^{-1}$ & 0.95 & 1.74 & 2.53 \\
\hline $\mathrm{HHV} \mathrm{MJkgOW}^{-1}$ & 2.38 & 4.54 & 9.21 \\
\hline
\end{tabular}

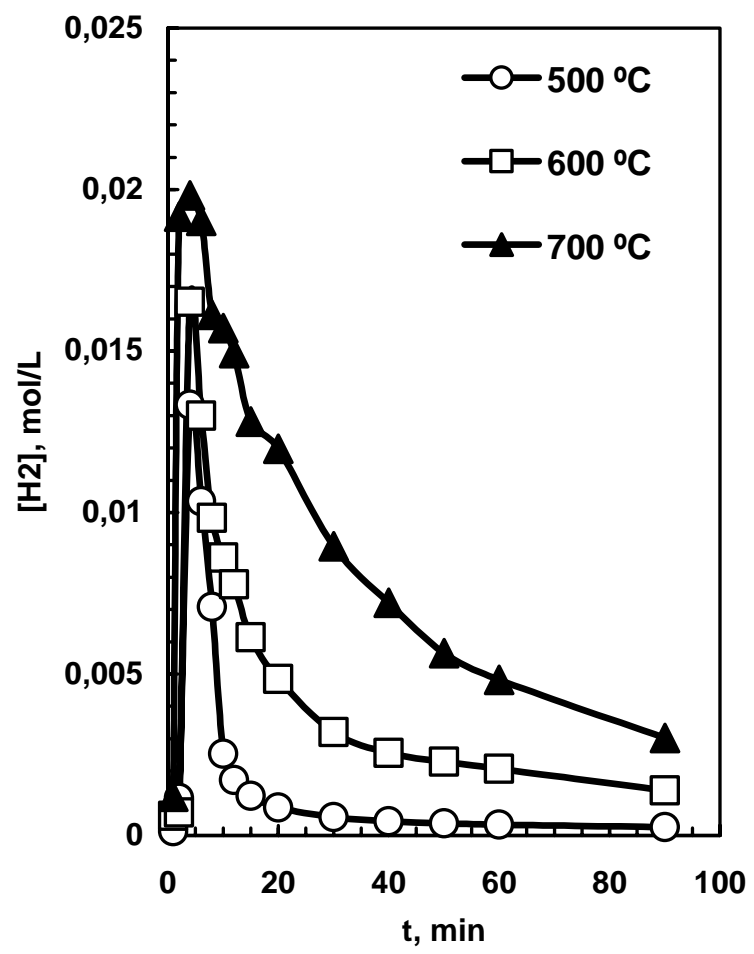

Figure 2. Hydrogen concentration. Influence of temperature.

\section{Steam flow rate influence}

Three experiments $\left(0.82,1.40\right.$ and $\left.2.37 \mathrm{mLmin}^{-1}\right)$ were carried out to study the influence of steam flow rate. In this set of experiments, the initial mass of residue was 10 $\mathrm{g}$, the mass of dolomite in the second reactor $100 \mathrm{~g}$. and the temperature $700{ }^{\circ} \mathrm{C}$. Table 7 list the fraction yields, the proximate analysis and HHV of the chars. For comparison, the results of an experiment in which steam was not used, are included.

As it is logical, results are in all cases very similar. Effectively, as it has been indicated, the pyrolysis has place in the first reactor, while the steam is introduced in the second reactor. In consequence, the obtained coal and his properties are independent of the presence of the steam. 
Table 7. Steam flow rate influence. Fractions yields, proximate analysis and HHV of chars.

\begin{tabular}{|l|c|c|c|c|}
\hline $\begin{array}{l}\text { Steam flow rate, } \\
\text { mLmin }^{-1}\end{array}$ & 0.0 & 0.82 & 1.40 & 2.37 \\
\hline Char, wt\% & 23.1 & 23.2 & 22.9 & 23.2 \\
\hline Liquid, wt\% & 35.3 & 35.2 & 35.5 & 35.6 \\
\hline Gas, wt\% & 41.6 & 41.6 & 41.6 & 41.2 \\
\hline Fixed Carb., wt\% & 86.3 & 86.4 & 86.4 & 86.5 \\
\hline Volatiles, wt\% & 7.2 & 7.3 & 7.2 & 7.3 \\
\hline Ash, wt\% & 6.5 & 6.3 & 6.4 & 6.2 \\
\hline${\text { HHVChar, } \mathrm{MJkg}^{-1}}^{-3}$ & 30.9 & 30.6 & 30.7 & 31.0 \\
\hline
\end{tabular}

Table 8 lists the influence of steam flow rate on the gas production and the HHV of the gas fraction. Differences are not significative. The methane and monoxide productions remain basically constant in the different experiments. Only hydrogen and dioxide productions increase when the steam flow rate is larger. In any case, the experiments carried out with 1.40 and $2.37 \mathrm{mLmin}^{-1}$ of steam flow rate originate identical productions of hydrogen. As a consequence of these tendencies, the HHV also experiments a small increase, achieving a maximum value of $9.25 \mathrm{MJkgOW}^{-1}$.

Table8. Steam flow rate influence. Gases production and HHV of gases.

\begin{tabular}{|l|c|c|c|c|}
\hline $\begin{array}{l}\text { Steam flow rate, } \\
\text { mLmin }^{-1}\end{array}$ & 0 & 0.82 & 1.40 & 2.37 \\
\hline $\mathrm{H}_{2}$, moleskgOW $^{-1}$ & 16.1 & 19.3 & 20.5 & 20.6 \\
\hline $\mathrm{CO}$, moleskgOW $^{-1}$ & 3.86 & 3.82 & 3.93 & 3.98 \\
\hline $\mathrm{CO}_{2}$, moleskgOW $^{-1}$ & 1.84 & 5.30 & 4.85 & 4.99 \\
\hline $\mathrm{CH}_{4}$, moleskgOW $^{-1}$ & 2.39 & 2.40 & 2.53 & 2.51 \\
\hline $\mathrm{HHV}_{\mathrm{MJkgOW}}$ & 7.82 & 8.73 & 9.21 & 9.25 \\
\hline
\end{tabular}

\section{Energy evaluation}

As it has been indicated, the pyrolysis of olive oil waste yields three phases: solid, liquid and gas, the latter two containing a wide variety of components. As far as energy recovery is concerned, the most appropriate phases would be solid and gas. The liquid phase, once separation problems are overcome, could be useful for the recovery of certain important components.

The energy value of the solid phase is based on the carbon content. Another possibility of use would be to carry out gasification to obtain activated carbon or gases. The energy value of the gases is effectively their heating power. As can be observed in tables 2, 4, 6 and 8, the $\mathrm{HHV}$ of the gases increases with increasing temperature and dolomite mass as a consequence of the greater gas yield, including hydrogen. On the other hand, the highest heating value of the solid obtained remains practically constant, because to the profit in fixed carbon resists the loss of volatile, compensating both contributions in the total HHV. Taking these factors into account, the most appropriate working temperature would probably $700{ }^{\circ} \mathrm{C}$, where charcoals with the highest heating value are obtained with satisfactory contents of fixed carbon and volatile matter, and the HHV of the gases is maximum.

\section{Conclusion}

The pyrolysis and catalytic steam gasification of olive oil waste leads to three phases (solid, liquid and gaseous), whose yields are strongly dependent on temperature and on presence of dolomite under the conditions of this study. The characteristics of the solid phase, established by proximate analysis, vary as follows: an increase in temperature leads to an increase in fixed carbon content, a slight increase in ash content, and a decrease in volatile matter. The gas distribution varies notably with temperature, with increasing formation of $\mathrm{H}_{2}, \mathrm{CO}, \mathrm{CH}_{4}$ and $\mathrm{CO}_{2}$.

The mass of dolomite used as catalyst exerts a positive effect on the generation of gases. When the mass of catalyst is increased, the liquid fraction decreases and the gaseous increases. Between the gases, the hydrogen experiments important variations (double your production), while the monoxide, dioxide and methane do not vary significantly. As a consequence of the above, the HHV of the gaseous fraction increases.

On the other hand, the catalyst is very stable and does not lose activity during at least six cycles of pyrolysisgasification.

The presence of steam as reagent favours the production of hydrogen and carbon dioxide, while the production of monoxide and methane do not get modified. In any case, for steam flow rate higher than $1.40 \mathrm{mLmin}^{1 \text {, changes in }}$ the studied parameters are not observed.

According to the characteristics and energy contents, the solid phase can be used as fuel, precursor for the manufacture of activated carbons or briquettes. The liquid phase could be used as liquid fuel or as organiccompounds source. Finally, the gas phase could be used to heat the pyrolysis reactor or to generate heat and electricity in a gas-turbine/vapour-turbine combined cycle.

\section{Acknowledgments}

The authors express their gratitude to the "Junta de Extremadura" for the financial support received to perform this study by means of Project No. 2PR04B016.

\section{References}

[1] Hohenstein, W.G., Wright, L.L., 1994. Biomass energy production in the United States: an overview. Biomass and Bioenergy. 6, 161-173

[2] B. McNelis, G. van Roekel, K. Preiser. Renewable energy technology for developing countries, the future for renewable energy: prospects and directions, EUREC Agency, London. 
[3] F. McGowan. Controlling the greenhouse effect: the role of renewables. Energy Policy 19 (1991) 111-118.

[4] G. Taralas, M.G. Kontominas. Pyrolysis of solid residues commencing from the olive oil food industry for potential hydrogen production. J. Anal. Appl. Pyrolysis 76 (2006) 109-116.

[5] G. Taralas, M.G. Kontominas, in: A.V. Bridgwater (Ed.), Science in Thermal and Chemical Biomass Conversion, Victoria, Vancouver Island, BC, Canada, 30 August-2 September 2004.

[6] K. Sjöström, G. Taralas, L. Liinanki, in: A.V. Bridgwater, J.L. Kuester (Eds.), Research in Thermochemical Biomass Conversion, Elsevier Science, London, UK, 1988, p. 974.

[7] F. Ates, A. E. Pütün, E. Pütün. Pyrolysis of two different biomass samples in a fixed-bed reactor combined with two different catalysts. Fuel 85 (2006) 1851-1859.

[8] G. Hu, S. Xu, S. Li, C. Xiao, S. Liu. Steam gasification of apricot stones with olivine and dolomite as downstream catalysts. Fuel Process. Technol. 87 (2006) 375-382.

[9] J.M. Encinar, J.F. González, J.J. Rodriguez, M.J. Ramiro. Catalysed and uncatalysed steam gasification of eucalyptus char: influence of variables and kinetic study. Fuel 80 (2001) 2025-2036
[10] J.M. Encinar, J.F. González, J. González. Steam gasification of Cynara cardunculus L.: influence of variables. Fuel Process. Technol. 75 (2002) 27-43.

[11] J.F. González, J.M. Encinar, J.L. Canito, E. Sabio, M. Chacón. Pyrolysis of cherry stones: energy uses of the different fractions and kinetic study. J. Anal. Appl. Pyrolysis 67 (2003) 165-190

[12] J.M. Encinar, F.J. Beltrán, A. Bernalte, A. Ramiro, J.F. González. Pyrolysis of two agricultural residues: Olive and Grape Bagasse. Influence of particle size and temperature. Biomass and Bioenergy, 11 (1996) 397-409.

[13] J.M. Encinar, F.J. Beltrán, J.F. González, M.J. Moreno. Pyrolysis of Maize, Sunflower, Grape and Tobacco Residues. J. Chem. Tech. Biotechnol. 70 (1997) 400-410.

[14] K.H. van Heek, B.O. Strobel, W. Wanzl. Coal utilization process and their application to waste recycling and biomass conversion. Fuel 73 (1994) 1135-1143.

[15] Association Francaise de Normalisation, Charbon de bois et briquettes de charbon de bois à usage domestique: denomination, spécifications, essais. AFNOR 84361 NF B 55-101, 1985

[16] Institut Belge Normalisation (IBN), Charbon de bois et briquettes de charbon de bois à usage domestique: denomination, spécifications, essais. NBN M 11-001, 1984 